\title{
THE THEORY OF GLACIER SLIDING
}

\author{
By J. Weertman
}

(U.S. Army Cold Regions Research and Engineering Laboratory, Hanover, New Hampshire, U.S.A. and Department of Materials Science and Department of Geology, Northwestern University, Evanston, Illinois, U.S.A.)

\begin{abstract}
The theory of the sliding of glaciers presented by the author in earlier papers has been generalized (I) by taking into account the resistance to sliding offered by obstacles both smaller and larger than the controlling obstacles and (2) by relaxing the assumption that ice is always in intimate contact with the bed at the down-stream side of an obstacle. The sliding velocities and controlling obstacle sizes which are found from the generalized theory are approximately the same as those found from the earlier theory. A new result obtained from the present theory is that a water layer an order of magnitude smaller in thickness than the height of the controlling obstacles can cause an appreciable increase in the sliding velocity. The generalized theory contains Lliboutry's sliding theory as an extreme limiting case. For certain thicknesses of a glacier the sliding velocity is a double-valued function of the shear stress exerted at the bed.
\end{abstract}

RÉsumé. La théorie du glissement des glaciers présentée par l'auteur dans de précédents articles est généralisée ( $\mathrm{I}$ ) en tenant compte de la résistance au glissement présentée par des obstacles plus petits ou plus grands que les obstacles de taille critique, (2) en abandonnant l'hypothèse que la glace est toujours en contact direct avec le lit en aval d'un obstacle. Les vitesses de glissement et les dimensions des obstacles de taille critique que l'on trouve à partir de la théorie généralisée sont approximativement les mémes que celles trouvées dans les théories précédentes. Un résultat nouveau obtenu à partir de la théorie actuelle est qu'une couche d'eau dont l'épaisseur est plus petite de un ordre de grandeur que la hauteur des obstacles de taille critique, peut causer un accroissement appréciable de la vitesse de glissement. La théorie généralisée englobe la théorie du glissement de Lliboutry considérée comme un cas limite. Pour certaines épaisseurs d'un glacier la vitesse de glissement est une fonction à deux solutions du cisaillement exercé contre le lit.

Zusammenfassung. Die Theorie des Gletschergleitens, die der Verfasser in früheren Veröffentlichungen vorgelegt hat, wurde verallgemeinert (I) durch Berücksichtigung des Gleitwiderstandes an Hindernissen, die einerseits kleiner, anderseits grösser als die kritischen Hindernisse sind, und (2) durch Aufgabe der Annahme, dass Eis immer in enger Berührung mit dem Untergrund auf der stromabwärts gelegenen Seite eines Hindernisses ist. Die Gleitgeschwindigkeiten und kritischen Hindernisgrössen, die sich aus der verallgemeinerten Theorie ergeben, stimmen annähernd mit denen der früheren Theorie überein. Die vorliegende Theorie liefert das neue Ergebnis, dass eine Wasserschicht, deren Dicke um eine Grössenordnung kleiner ist als die Höhe der kritischen Hindernisse, einen merklichen Anstieg der Gleitgeschwindigkeit verursachen kann. Die verallgemeinerte Theorie schliesst Lliboutry's Gleittheorie als einenextremen Grenzfall mit ein. Für bestimmte Gletscherdicken ist die Gleitgeschwindigkeit eine doppelwertige Funktion der Scherspannung am Untergrund.

\section{INTRODUGTION}

Until recently the amount of experimental research devoted to the study of the sliding of glaciers has been quite limited. Whatever understanding we had of this phenomenon came principally from theoretical work (Weertman, I957, I958, I962; Lliboutry, I959; [Union Géodésique et Géophysique Internationale], I 963 , p. 61-68; in press). The situation now is changing. Kamb and LaChapelle (1963, 1964) have carried out extremely interesting field studies and laboratory tests on the mechanisms involved in glacier sliding. Lliboutry and Brepson (1963) have constructed a large machine in which $30 \mathrm{~kg}$. blocks of ice will be made to slide. Elliston ([Union Géodésique et Géophysique Internationale], i963, p. 65-66) has shown from field work on the Gornergletscher that (melt) water at the bottom of a glacier profoundly influences the sliding velocity.

It seems likely that the phenomenon of glacier sliding will be the subject of an active field of research in the near future. Obviously data have been and will be obtained which can be used to test quantitatively the theories on glacier sliding. It is desirable that the theories themselves be developed as completely as possible for these tests.

It is the purpose of this paper to develop a sliding theory which is more general than that previously presented (Weertman, 1957, 1958, I962; [Union Géodésique et Géophysique Internationale], in press). One improvement incorporated into the new theory is the fact that whereas in the previous version all resistance to sliding comes from a "controlling protuberance size", now the resistance produced by other sizes of obstacles is considered. The resistance 
offered by the other obstacles is smaller than that caused by the controlling obstacles; nevertheless it is appreciable and should be taken into account.

Another improvement in the present theory comes from the relaxation of the assumption made in the older version that the hydrostatic pressure at the bottom of a glacier always is larger than any possible tensile stress occurring there. In the newer theory account is taken of situations in which this assumption is not valid.

It is hoped that the present version of the theory and the discussion of certain of its features will permit a more meaningful quantitative test of the theory from the field and experimental data which should be forthcoming in the near future.

\section{THEORY}

Two sliding mechanisms form the basis of the theory. One of these involves the phenomenon of pressure melting. In this mechanism ice is melted on the up-stream, high-pressure side of an obstacle. The water produced flows around the obstacle to the low-pressure side where it refreezes. The velocity of melting and freezing, and thus of ice motion, is determined by the temperature gradient across the obstacle. This gradient is larger the smaller the obstacle, and thus the speed of sliding is larger the smaller the obstacle size. The pressure-melting mechanism permits relatively fast ice motion past small obstacles but not around large obstacles. A second sliding mechanism was introduced in order to obtain motion of ice around large protuberances. This mechanism is based on the enhancement of the creep rate caused by stress concentrations existing near obstacles. It leads to a sliding velocity which increases with increasing obstacle size. The existence of both of these mechanisms has been verified by the field observations of Kamb and LaChapelle at the end of the ice tunnel in Blue Glacier. The basis of our theory is thus established and no longer need be regarded as speculative.

In my original paper I postulated the existence of an idealized glacier bed containing cubical obstacles. The assumption that the obstacles have a cubic shape was one of convenience. It is obvious that essentially identical results would be obtained from the analysis if the exact shape of the obstacles were left unspecified and only their average dimension were used in the equations. In order to make the sliding theory more general we shall consider in this paper obstacles whose three dimensions do differ from one another. We let $L_{\mathrm{h}}$ represent the average height of an obstacle, and $L_{\mathrm{d}}$ and $L_{\mathrm{p}}$ represent respectively the average widths in the direction of glacier flow and in the direction perpendicular to the flow. It is not necessary to specify the exact shape of the obstacles.

It was shown in the original paper that if the obstacles in a glacier bed all are of the same size a definite sliding velocity can be calculated from each of the two sliding mechanisms. In order to make this calculation it is necessary to assume that a shear stress cannot be supported across a smooth rock-ice interface. This assumption obviously is valid if the ice is at the melting point and a thin film of water exists between the rock and the ice. It is not valid if the ice is below its melting point. Thus cold glaciers or ice sheets should not slip at their bed, a conclusion borne out by at least one field observation (Goldthwait, ig6o).

Consider a bed containing obstacles of uniform size which are separated from one another by an average distance $L^{\prime}$. The average force exerted on any one obstacle is $\tau L^{\prime 2}$ when a shear stress $\tau$ acts parallel to the bed provided that a film of water exists between the rock at the bed and the ice of the glacier. If the ice exerts a force on an obstacle then conversely the obstacle pushes through the ice with the same force $\tau L^{\prime 2}$. Since the average cross-sectional area of an obstacle is $L_{\mathrm{h}} L_{\mathrm{p}}$, this force produces a compressional stress approximately equal to $\tau L^{\prime 2} / L_{\mathrm{h}} L_{\mathrm{p}}$ on the up-stream side of the obstacle. A stress of this magnitude should exist within a volume of ice of the same size as the obstacle itself.

In his review of the original (unpublished) version of my first paper (Weertman, I957) on glacier sliding J. W. Glen, in a private communication, pointed out that the force exerted on the ice by an obstacle results not only in the existence of a compressive stress on the up-stream 
side of the obstacle but it also may cause the ice to experience a tensile stress on the downstream side. In order that this tension exist it is necessary that the ice does not lose contact with the rock surface. Thus if the hydrostatic pressure is great enough to prevent a cavity from being formed on the down-stream side of an obstacle, the obstacle produces not only compression in the ice on its up-stream side but also tension on its down-stream side. (The tensile and compressive stresses we are discussing are stresses additional to the hydrostatic pressure normally present at the bottom of the glacier.) It is obvious that if the obstacle is symmetric the tensile stress is of the same magnitude as the compressive stress. If ice is to close in behind an obstacle as it flows around it the flow lines on the up-stream and down-stream side of a symmetric obstacle must be symmetric and the stresses causing this flow likewise must be symmetric. Therefore when Glen's condition is valid and the compressive stress is $\tau L^{\prime 2} / 2 L_{\mathrm{h}} L_{\mathrm{p}}$ and the tensile stress also is equal to $\tau L^{\prime 2} / 2 L_{\mathrm{h}} L_{\mathrm{p}}$. The combination of these two stresses represents a total force of $\tau L^{\prime 2}$ exerted on the obstacle.

If the hydrostatic pressure is not great enough to prevent the formation of a cavity on the down-stream side of an obstacle the compressive stress on the up-stream side is $\tau L^{\prime 2} / L_{\mathrm{h}} L_{\mathrm{p}}$, a value which is twice as great as that which is realized when Glen's condition holds. * In the published version of the sliding theory (Weertman, I957) it was assumed that Glen's condition always is satisfied.

In this paper we shall consider situations in which Glen's condition is valid and those in which it is not.

\section{Pressure melting}

The velocity of sliding caused by pressure melting is found from a calculation of the change in hydrostatic pressure from one side of an obstacle to another. Because the melting temperature of ice varies with pressure, there is a temperature difference across the obstacle which gives rise to the flow of heat, the melting of ice, and the freezing of water. The difference in temperature $\Delta T$ is equal to $C \Delta P$, where $C$ is a constant equal to $7 \cdot 4 \times 10^{-9}{ }^{\circ} \mathrm{C}$. $\mathrm{cm}^{2} / \mathrm{dyn}$. and $\Delta P$ is the difference in hydrostatic pressure.

There is some ambiguity connected with the pressure difference $\Delta P$. In the water layer existing between the ice and rock the pressure difference will be $\Delta P=\tau L^{\prime 2} / L_{\mathrm{h}} L_{\mathrm{p}}$. In the ice itself, however, the difference may be only $\tau L^{\prime 2} / 3 L_{\mathrm{h}} L_{\mathrm{p}}$. The factor of $\frac{1}{3}$ in this latter expression arises because a uniaxial compression or tension produces a hydrostatic pressure of only $\frac{1}{3}$ the magnitude of the compressive or tensile stress. (That is, through a rotation of the coordinate system, a uniaxial stress in one coordinate system can be changed in another coordinate system to a stress system containing only pure shear stresses and a hydrostatic stress. The value of the hydrostatic stress turns out to be $\frac{1}{3}$ the value of the original uniaxial compressive or tensile stress.) In our previous papers on sliding we assumed that the factor $\frac{1}{3}$ should appear in the equations. On the other hand, Kamb and LaChapelle (1964) consider that it should not. This is a question best answered by experiment, and Kamb and LaChapelle's (limited) experimental

* If the ice is cold and frozen to a rock surface the ice-rock interface can support a tensile force normal to it. In this situation a tensile stress could exist on the down-stream side of an obstacle even when the hydrostatic pressure is small. It also should be realized that even if ice is at the melting point an ice-water-rock interface might be able to support a tensile force across it since liquids do have an appreciable tensile strength. The hydrostatic tensile strength of water has been measured by Briggs (1950). He finds it to rise steeply with temperature from 20 bars at a temperature slightly above $0^{\circ} \mathrm{C}$. to 280 bars at temperatures between $5^{\circ}$ to $10^{\circ} \mathrm{C}$. Fisher ( 1950 ), has pointed out that the drop in strength by an order of magnitude with a small decrease in temperature may be caused by the nucleation of ice under the reduced hydrostatic pressure. It would be desirable to have an experimental measure of the tensile strength of water in contact with an ice surface to see if it still has a finite value under these conditions.

For a liquid to have a tensile strength it must be in a confined space. This condition may not be met at the bottom of a glacier and the tensile strength of the water layer could be zero. Nevertheless in laboratory experiments, such as those carried out by Kamb and LaChapelle in which blocks of rock are pulled through ice, it is possible that a tensile stress is exerted across the water layer separating ice from rock since in this type of experiment the water layer may be confined. 
data do seem to support their viewpoint. Therefore in what follows we shall consider that the temperature difference across an obstacle is $C \tau L^{\prime 2} / L_{\mathrm{h}} L_{\mathrm{p}}$ rather than the smaller value we used previously. The temperature gradient across the obstacle is $C \tau L^{\prime 2} / L_{\mathrm{h}} L_{\mathrm{p}} L_{\mathrm{d}}$. If all the heat flow is through the obstacle a volume of ice is melted in a unit time which equals the temperature gradient $\left(C_{\tau} L^{\prime 2} / L_{\mathrm{h}} L_{\mathrm{p}} L_{\mathrm{d}}\right)$ times the area of an obstacle $\left(L_{\mathrm{h}} L_{\mathrm{p}}\right)$ times the coefficient of thermal conductivity $D$ of the rock divided by $H \rho$, where $H$ is the heat of fusion of ice (8o cal./g.) and $\rho$ is the density of ice. The velocity of sliding is equal to this volume of melted ice divided by the area of an obstacle. The following equation is obtained for the velocity of the sliding $S_{\mathrm{I}}$ which results from pressure melting:

$$
S_{\mathrm{I}}=C \tau L^{\prime 2} D / H \rho L_{\mathrm{h}} L_{\mathrm{p}} L_{\mathrm{d}}=(C \tau D / H \rho L)\left(L^{\prime 2} / L^{2}\right)
$$

where $L$ is the average dimension of an obstacle $\left(L^{3}=L_{\mathrm{h}} L_{\mathrm{p}} L_{\mathrm{d}}\right)$. Except for the absence of a factor of $\frac{1}{3}$ equation (ra) is identical to the equation previously obtained for the pressuremelting mechanism. Equation (ra) is derived with the assumption that all the heat flows through the obstacle and none goes through the surrounding ice. To take this latter heat flow into account we rewrite equation (ra) as follows:

$$
S_{\mathrm{I}}=\alpha C \tau L^{\prime 2} D / H \rho L_{\mathrm{h}} L_{\mathrm{p}} L_{\mathrm{d}}=(\alpha C \tau D / H \rho L)\left(L^{\prime 2} / L^{2}\right)
$$

where $\alpha$ is a constant whose value is $\mathrm{I}$ if all of the heat flow is confined to the obstacle and is somewhat larger than $\mathrm{I}$ if additional heat flows through the ice. The value of $a$ could be determined by laboratory experiments.

\section{Stress concentrations}

The velocity of the sliding which results from the creep-rate enhancement caused by stress concentrations is found by noting that the volume of ice which is subjected to the concentrated stress is of the order of the volume of the obstacle itself. The creep rate $\dot{\epsilon}$ of ice is given by Glen's creep law. It is

$$
\dot{\epsilon}=B \sigma^{n}
$$

where $\sigma$ is the stress, $n$ is a constant equal to 3 or 4 , and $B$ is another constant which is equal to $0 \cdot 0$ I $7 \mathrm{bar}^{-n} / \mathrm{yr}$. when the stress is uniaxial tensile or compressive. The compressive stress $\sigma$ on the up-stream side of an obstacle is equal to $\tau L^{\prime 2} \mid \beta L_{\mathrm{h}} L_{\mathrm{p}}$, where $\beta=2$ if the hydrostatic pressure is sufficiently large to prevent cavity formation and $\beta=\mathrm{I}$ if it is not. The sliding velocity $S_{2}$ caused by the stress concentration is equal to the creep rate $\dot{\epsilon}$ times the distance in the direction of motion over which this creep rate is effective. Thus

$$
S_{2}=\dot{\epsilon} L_{\mathrm{d}}=B L_{\mathrm{d}}\left(\tau L_{\mathrm{d}} / \beta L\right)^{n}\left(L^{\prime 2} / L^{2}\right)^{n}
$$

where, as before, $L$ is the average dimension of an obstacle. This sliding velocity is almost the same as that derived previously. The sliding velocity given by equation ( $3 \mathrm{a})$ is, of course, only a rough estimate of the sliding velocity $S_{2}$ since we do not know exactly the distance over which the creep rate $\dot{\epsilon}$ is effective. A more exact expression for the sliding velocity is

$$
S_{2}=b \dot{\epsilon} L_{\mathrm{d}}=b B L_{\mathrm{d}}\left(\tau L_{\mathrm{d}} / \beta L\right)^{n}\left(L^{\prime 2} / L^{2}\right)^{n}
$$

where $b$ is a constant of the order of $\mathrm{I}$. The exact value of $b$ could be determined from laboratory experiments.

\section{Double-valued nature of the sliding velocity due to stress concentrations}

It should be emphasized that in a certain range of values for the overburden pressure the sliding velocity $S_{2}$ actually is a double-valued function of the shear stress $\tau$. The reason for this multiplicity of value is the fact that $\beta$ may take on one of two possible values. We have noted that if the hydrostatic pressure is very large $\beta=2$ but if it is small $\beta=\mathrm{I}$. Suppose however that the hydrostatic pressure has an intermediate value. Let $P$ equal the hydrostatic pressure, where $P=\rho g h, \rho$ is the density of ice, $g$ is the gravitational acceleration, and $h$ is the thickness of the glacier. Let $T$ represent the tensile stress on the down-stream side of an obstacle. This 
tensile stress is exerted in a direction parallel to the bed. Further, let $\theta$ represent the maximum angle between the slope of the obstacle and the average slope of the bed. Thus $\theta$ is $90^{\circ}$ for an obstacle having part of its surface perpendicular to the average slope of the bed. The maximum tensile stress exerted normal to an ice-rock surface is $T \sin ^{2} \theta$. In order for a tensile stress to exist on the down-stream side of an obstacle the ice must remain in contact with the rock and thus the hydrostatic pressure must be larger than $T \sin ^{2} \theta$, where $T=\tau L^{\prime 2} / 2 L_{\mathrm{h}} L_{\mathrm{p}}$.

If the ice loses contact with the down-stream surface of an obstacle only a compressive stress exists on the up-stream side of the obstacle. Its magnitude is $\tau L^{\prime 2} / L_{\mathrm{h}} L_{\mathrm{p}}$. A cavity will form on the down-stream side. The hydrostatic pressure will tend to close the cavity. The rate of closure (Nye, I953) is proportional to $P^{n}$. However the cavity is being opened up by ice flow around the obstacle. If $P$ is greater than $\tau L^{\prime 2} / L_{\mathrm{h}} L_{\mathrm{p}}$ a cavity will not be able to form. On the other hand if $P$ is less than $\tau L^{\prime 2} / L_{\mathrm{h}} L_{\mathrm{p}}$ a cavity can remain open. The value of $P$ can be smaller than $\tau L^{\prime 2} / L_{\mathrm{h}} L_{\mathrm{p}}$ and yet be larger than $T L^{\prime 2} \sin ^{2} \theta / 2 L_{\mathrm{h}} L_{\mathrm{p}}$, the stress which it must exceed to prevent an ice-rock interface surface from separating and a cavity being formed. Therefore at any value of $P=\rho g h$ in the range

$$
\tau L^{\prime 2} \sin ^{2} \theta / 2 L_{\mathrm{h}} L_{\mathrm{p}}<\rho g h<\tau L^{\prime 2} / L_{\mathrm{h}} L_{\mathrm{p}}
$$

a cavity which is formed behind an obstacle will remain open but if the cavity is not already in existence it will not form. Therefore $\beta$ can equal either I or 2 in this range of values of $P$. As a result the sliding velocity is double valued.

\section{The glacier sliding velocity}

In our previous papers on sliding it was found that the actual sliding velocity of a glacier whose bed contains a full spectrum of obstacle sizes is determined by those obstacles for which $S_{1}=S_{2}$. It was argued that the pressure-melting mechanism enables ice to flow easily around smaller obstacles because this mechanism gives a sliding velocity which is larger the smaller the obstacle. It was argued further that the stress-concentration mechanism enables ice to flow around the larger obstacles without any trouble since for this mechanism the larger the obstacle the greater is the sliding velocity.

We still hold to this viewpoint but we wish to refine the calculation of the actual sliding velocity. In the previous paper it was assumed implicitly that only the "controlling" obstacles, that is, those obstacles whose size is such that $S_{1}$ and $S_{2}$ of equations (I b) and (3) are equal, hinder the ice flow. The resistance offered by obstacles both smaller and larger than the controlling obstacles was considered to be negligibly small. This assumption obviously is only an approximation. The smaller and the larger obstacles also hinder the ice motion although not to the same degree as the controlling protuberances.

We wish now to calculate the sliding velocity of a glacier when the effect of obstacles both smaller and larger than the controlling protuberances is taken into account.

It is postulated that the glacier bed is made up of obstacles of various sizes. One simplification will be made in the distribution of obstacle sizes. It will be assumed that instead of being continuous the spectrum of sizes is discrete. If $\lambda$ is regarded as the average dimension of the smallest obstacle the next largest obstacle will be taken to have the average dimension $\operatorname{\text {I}} \lambda$, the next largest $\operatorname{Ioo} \lambda$, the next $\operatorname{I} \operatorname{ooo} \lambda$ and so on to the largest sized obstacles (which could be of the order of $\frac{1}{10}$ of the thickness of the glacier).

Because of the existence of the shear stress $\tau$, a glacier transmits over an area $A$ a total force $\tau A$ to the bed of the glacier. This force is transmitted through the obstacles and thus each size group will transmit some fraction of the total force. The obstacles in the controlling size group will, of course, transmit the major portion of the force. Suppose we let $\tau_{i} A$ represent that force which the obstacles of size $(\mathrm{I} 0)^{i} \lambda$ transmit to the bed. We must have the condition that $\Sigma \tau_{i} A=\tau A$, or

$$
\sum_{i=0} \tau_{i}=\tau .
$$


The stress $\tau_{i}$ can be regarded as the effective shear stress which causes the flow of ice around obstacles of the size $(\text { Io })^{i} \lambda$. Since the sliding velocity must be the same for every sized obstacle it follows that

$$
S=\left(S_{\mathrm{I}}+S_{2}\right)_{i}=\left(\alpha C \tau_{i} D / H \rho L_{i}\right)\left(L^{\prime} i^{2} / L_{i}^{2}\right)+b B L_{\mathrm{d}_{i}}\left(\tau_{i} L_{\mathrm{d}_{i}} / \beta_{i} L_{i}\right)^{n}\left(L^{\prime} i^{2} / L_{i}^{2}\right)^{n}
$$

where $S$ is the actual sliding velocity of the glacier and the subscripts refer to the values of $L, L^{\prime}$, etc., for the particular size of obstacle. ${ }^{*}$

Equation (6) gives $\tau_{i}$ in terms of the sliding velocity $S$. If all of the values of $\tau_{i}$ are substituted into the summation term of equation (5) an equation is obtained which contains only the sliding velocity $S$ and the applied shear stress $\tau$ as the independent variables. The sliding velocity has been determined as a function of the shear stress acting at the bed of a glacier. By inspection it is obvious that this equation is a complicated one. A good approximation to this more exact equation can be found by observing that in equation (6) the first term on the right-hand side is predominant for obstacles smaller than the controlling size $\dagger$ whereas the last term predominates for obstacles larger than the controlling size. Thus we can make the approximation that $S=\left(S_{\mathrm{r}}\right)_{i}$ for the smaller obstacles, that $S=\left(S_{2}\right)_{i}$ for the larger, and that $S=\left(S_{1}+S_{2}\right)=2 S_{1}=2 S_{2}$ for the controlling obstacle size.

Now let $\Lambda$ represent the average overall dimension and $\Lambda_{\mathrm{d}}$ the dimension in the direction of motion of the controlling obstacles. Let us assume that the "roughness" of the bed is not a function of the size of obstacles. Therefore $L^{\prime}{ }_{i} / L_{i}=r$ is constant for all obstacle sizes. The term $r$ is a measure of the roughness of the bed. Also let $L_{\mathrm{d}_{i}} / L_{i}=\gamma$ be a constant independent of obstacle size. Let $\tau_{\Lambda}$ represent the effective shear stress acting on the controlling obstacles. Since the sliding velocity is identical for all obstacles the effective shear stresses acting on obstacles smaller than the controlling size are $\tau_{\Lambda} / 5, \tau_{\Lambda} / 5^{\circ}, \tau_{\Lambda} / 5^{\circ 0}$, etc. Similarly, the effective shear stresses acting on the larger obstacles are $\tau_{\Lambda}\left(\beta / \beta_{\Lambda}\right) / 5^{\mathrm{I} / n}, \tau_{\Lambda}\left(\beta / \beta_{\Lambda}\right) / 5^{0^{\mathrm{I} / n}}, \tau_{\Lambda}\left(\beta / \beta_{\Lambda}\right) / 5^{00} \mathrm{O}^{\mathrm{I} / n}$ etc., where $\beta_{A}$ is the value of $\beta$ for the controlling obstacles.

With these values for the stresses $\tau_{i}$ equation (5) reduces to

$$
\tau=\tau_{\Lambda}\left[(\mathrm{I} \mathrm{I} / 9)+2^{\mathrm{I} / n} /\left\{(\mathrm{IO})^{\mathrm{I} / n}-\mathrm{I}\right\}\right]
$$

when the value of $\beta$ for all the larger obstacles is identical to $\beta_{\Lambda}$ of the controlling obstacles. Since $n \approx 3$ this last equation reduces to

$$
\tau=2 \cdot 3 \mathrm{I} 4 \tau_{\Lambda} .
$$

If $\beta_{\Lambda}=\mathrm{I}$ for the controlling obstacle size but $\beta$ of the larger obstacles is equal to 2, equation (7b) becomes

$$
\tau=3 \cdot 405 \tau_{\Lambda}
$$

Equations $(7 \mathrm{~b})$ and $(7 \mathrm{c})$ represent two limiting cases.

It can be seen that the effective shear stress acting on the controlling protuberances is only about $\frac{1}{2}$ to $\frac{1}{3}$ of the applied shear stress. Thus an appreciable part of the resistance to sliding comes from obstacles other than the controlling obstacles. This additional resistance is provided principally by the obstacles which are larger than the controlling size.

If we substitute equations (7) into equation (6) and set $L_{i}=\Lambda$ and $S_{\mathrm{I}}=S_{2}$, we obtain the following expression for the sliding velocity of a glacier

$$
S=2 a C D r^{2} \tau \mid k H \rho \Lambda
$$

where $k$ represents the constant term of equations (7) and has a value which lies between

* In the previous papers on sliding we set $S=S_{1}$ for the obstacle size which corresponds to $S_{1}=S_{2}$. Since sliding is produced by two mechanisms it would have been more accurate to have set $S=\left(S_{1}+S_{2}\right)=2 S_{1}=2 S_{2}$ in those papers.

$\dagger$ Hereafter the controlling obstacle size will be defined to be the size of that obstacle for which the two sliding mechanisms give identical contributions to the sliding velocity. 
$2 \cdot 314$ and 3.405 . An expression for $\Lambda$ is derived from the condition that $S_{1}=S_{2}$ at the controlling obstacle size:

$$
\Lambda=\left(\alpha C D k^{n-1} \beta_{\Lambda}^{n} / H \rho b B r^{2 n-2} \gamma^{n-1} \tau^{n-1}\right)^{\frac{1}{2}} .
$$

The substitution of this expression into $(8 \mathrm{a})$ results in the equation

$$
S=2\left(\alpha C D b B \gamma^{n-1} / H \rho \beta_{\Lambda}^{n}\right)^{\frac{1}{2}}\left(\tau r^{2} / k\right)^{(n+\mathrm{r}) / 2} .
$$

This equation gives the sliding velocity of a glacier as a function of the shear stress acting at the bed of a glacier. Apart from a constant factor it is identical to the sliding velocity calculated previously. Both the sliding velocity and the controlling obstacle size derived previously (Weertman, 1957, 1962) can be obtained from these last two equations by setting $k=b=$ $\gamma=\mathrm{I}, a=\frac{1}{3}$ and $\beta_{\Lambda}=2$, and by dividing the right-hand side of equation (8b) by 2 .

Figure I shows plots of sliding velocity at constant stress versus the roughness factor $r$ of the bed. (The larger is $r$ the smoother is the bed.) Also shown in these plots is $A$, the controlling obstacle size, versus $r$. In the calculations for these plots it was assumed that $a=\mathrm{I}, n=3$, $\gamma=\mathrm{I}, b=\mathrm{I}, C=7.4 \times \mathrm{IO}^{-3}{ }^{\circ} \mathrm{C}$. $/$ bar, $B=0.0 \mathrm{I} 7 \mathrm{bar}-3 / \mathrm{yr} ., \quad D=0.005 \mathrm{cal} . /{ }^{\circ} \mathrm{C}$. sec. (a typical value for rocks), and $\tau=\mathrm{I} \cdot \mathrm{O}$ bar. In the figure one set of curves was found for $\beta_{\Lambda}=\mathrm{I}$ and $k=2 \cdot 3 \mathrm{I}$ and another set for $\beta_{\Lambda}=2$ and $k=2 \cdot 3 \mathrm{I}$. These values of $\beta_{\Lambda}$ and $k$ represent limiting cases. The set of values $\beta_{\Lambda}=\mathrm{I}$ and $k=3.405$ correspond to curves which are intermediate to those plotted.

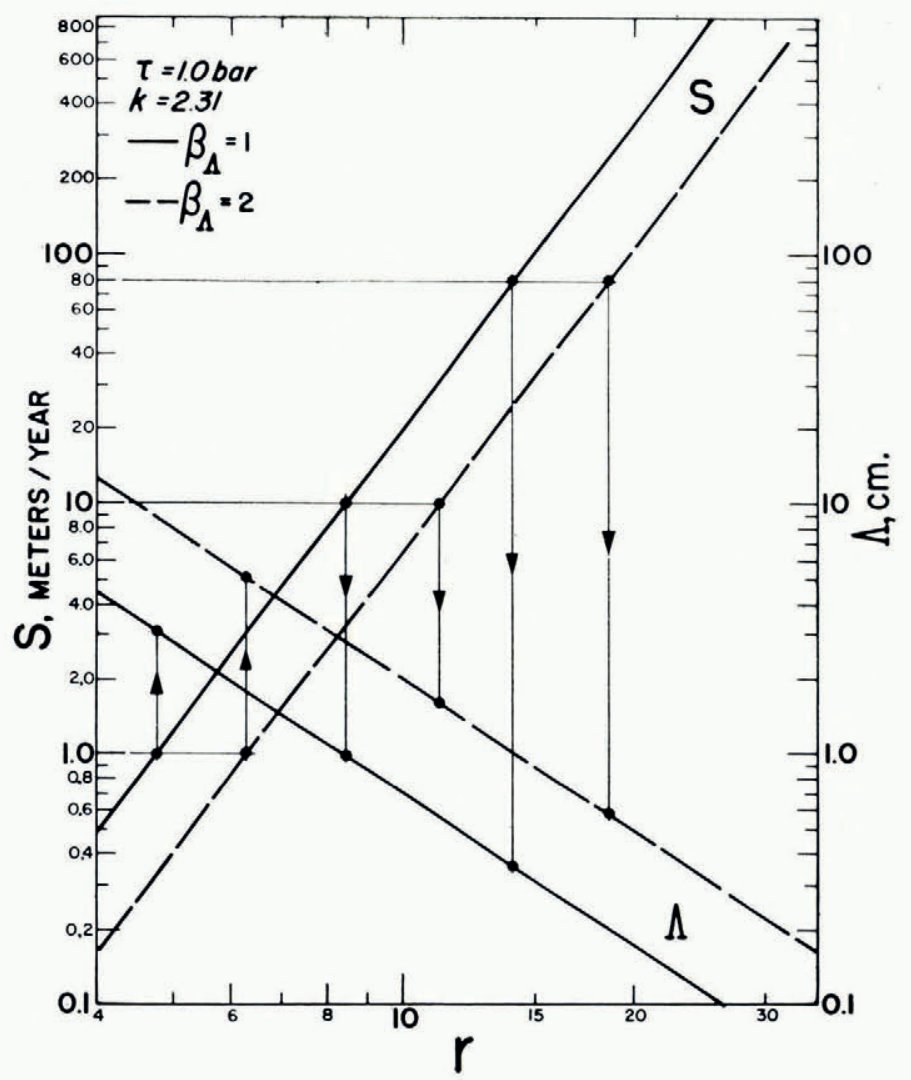

Fig. I. Plot of sliding velocity $S$ and size of controlling obstacles $\Lambda$ as a function of the roughness factor $r$ for a shear stress $\tau=I$ bar, $k=2 \cdot 3^{I}$ and $\beta_{\Lambda}=I$ or 2 . (The case of $k=3 \cdot 4$ and $\beta_{\Lambda}=I$ falls between the curves shown) 
In these plots the controlling obstacle size at a particular sliding velocity can be found by drawing a vertical line from the sliding velocity curve to the obstacle size curve. This is done in Figure I for a sliding velocity of $80 \mathrm{~m}$./yr., which is of the order of the sliding velocity of glaciers having a shear stress around $\mathrm{I}$ bar at their beds. The roughness factor of a glacier which slides with the velocity of $80 \mathrm{~m}$./yr. under a stress of I bar must be of the order of $r=I_{5}$ to 20. Also shown in Figure $\mathrm{I}$ are the obstacle sizes and roughness factors connected with sliding velocities of $\mathrm{I} 0 \mathrm{~m}$./yr. and $\mathrm{I} \cdot \mathrm{O} \mathrm{m}$./yr. under a $\mathrm{I}$ bar shear stress. A somewhat different method of presenting the results of equations (8) and (9) is shown in Figures 2 and 3 . Here we find plotted the sliding velocity and controlling obstacle size as a function of the shear stress for various values of the bed roughness.

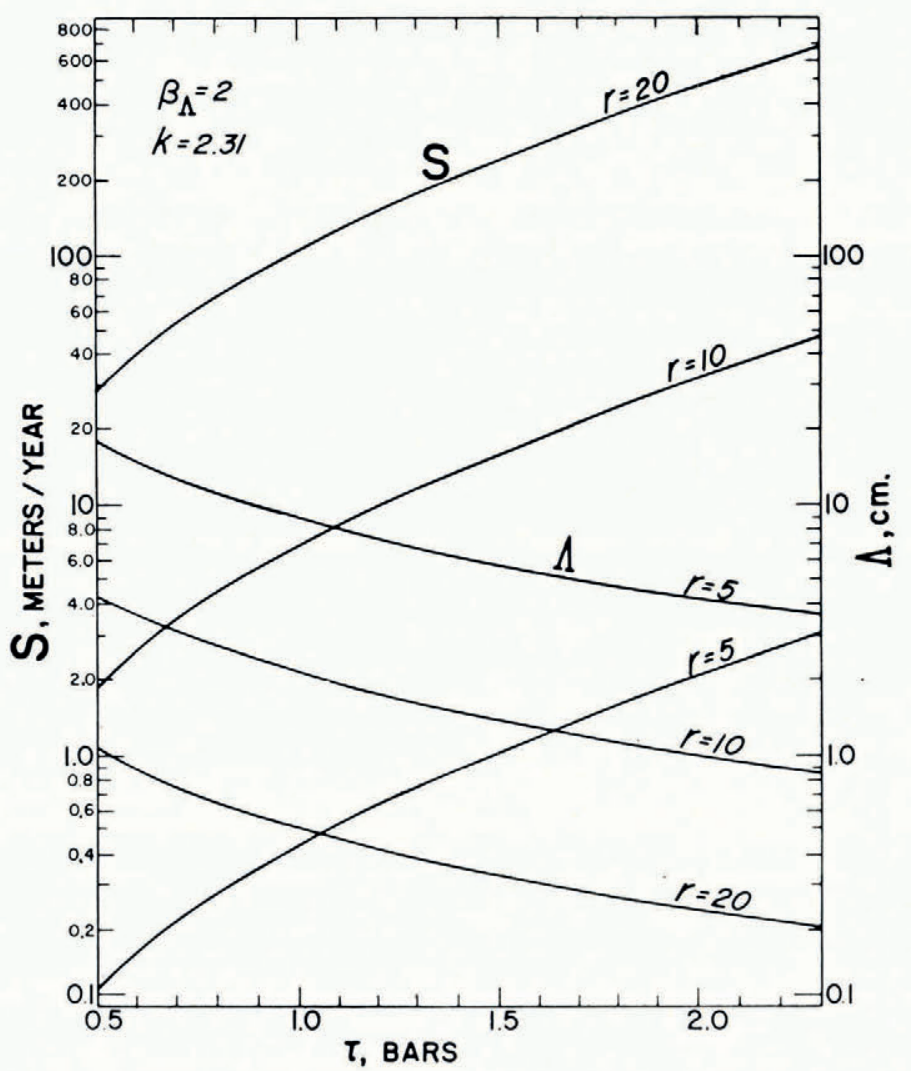

Fig. 2. Plot of sliding velocity $S$ and controlling obstacle size $\Lambda$ as a function of the shear stress $\tau$ for various values of the roughness factor $r$ and $k=2 \cdot 3 I$ and $\beta_{\Lambda}=2$

Kamb and LaChapelle (I964) measured a sliding rate of $5.8 \mathrm{~m} . / \mathrm{yr}$. at the end of their ice tunnel. They estimated that the roughness factor of the bed was equal to 9 and the shear stress acting on the bed was 0.7 bar. For these values of the roughness and the shear stress Figure 2 predicts a sliding rate of $2 \mathrm{~m}$./yr., a value close to the observed rate. The controlling obstacle size obtained from this plot is about $4 \mathrm{~cm}$. This size is comparable to the maximum thickness (about $3 \mathrm{~cm}$.) of the observed regelation layer. If the maximum thickness of the regelation layer is taken as an approximate measure of the controlling obstacle size, as was suggested by J. W. Glen at the Berkeley symposium, it would appear that theory and observation agree reasonably well. Nevertheless, Kamb and LaChapelle feel that the controlling 
obstacle size is much greater because the regelation layer behind the obstacles they examined appeared to be undeformed by creep. However, I pointed out ([Union Géodésique et Géophysique Internationale], in press) the improbability of finding an obstacle of a size exactly equal to the controlling obstacle size. It is only for this special size that the regelation and creep flow contribute comparable amounts to the total slippage. A given obstacle is more likely to be either smaller or larger than the controlling size. If it is smaller, flow of ice around it occurs predominately by regelation; if it is larger the flow takes place largely through creep deformation.

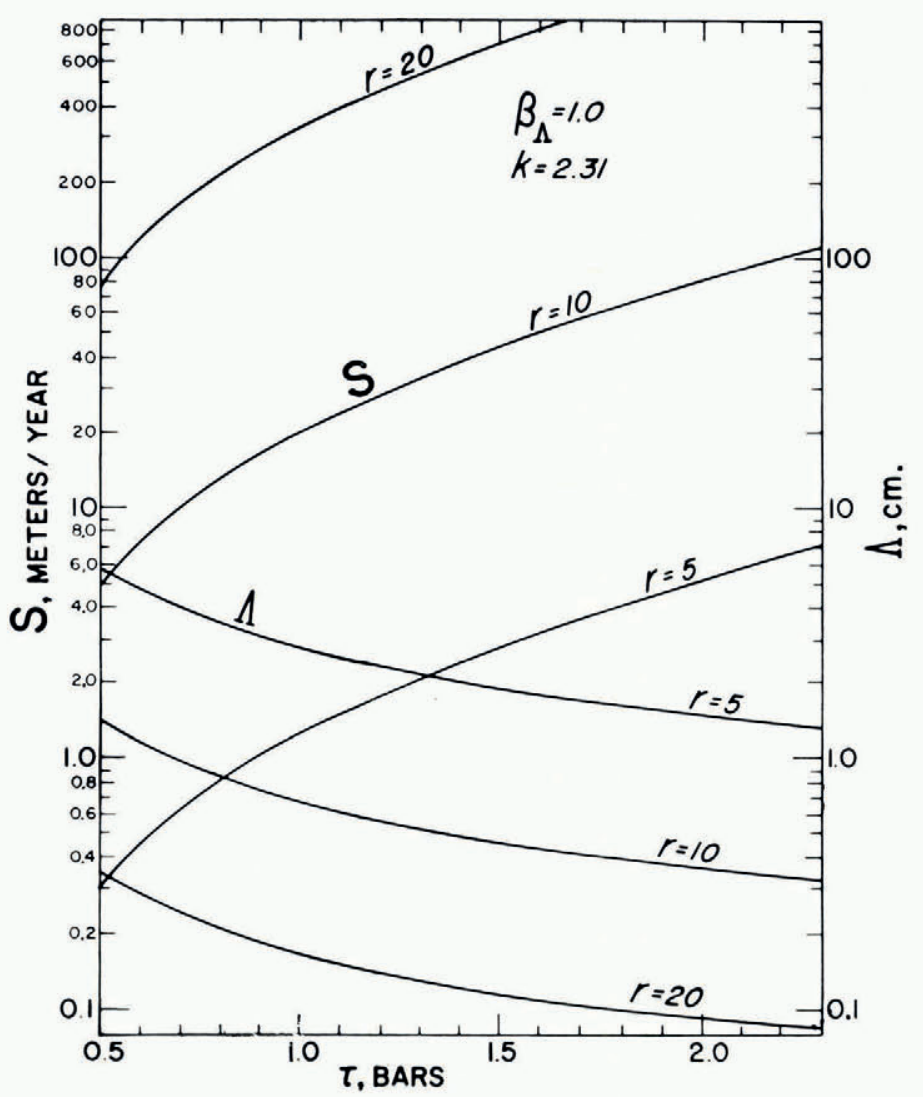

Fig. 3. Plot of sliding velocity $S$ and controlling obstacle size $\Lambda$ as a function of the shear stress $\tau$ for various values of the roughness factor $r$ and $k=2 \cdot 3 I$ and $\beta_{\Lambda}=I$

\section{Glen's condition}

The values of the sliding velocity and the controlling obstacle size depend upon whether or not Glen's condition is satisfied. Glen's condition is satisfied if the hydrostatic pressure $\rho g h$ is sufficiently large.

The effective stress on the controlling obstacles is $\tau r^{2} / \beta_{A} k$, where $\beta_{A}=2$ when Glen's condition holds and $\beta_{\Lambda}=\mathrm{I}$ when it does not. If the hydrostatic pressure $\rho g h$ is greater than $\tau r^{2} / k$, Glen's condition always is valid; if $\rho g h$ is less then $\tau r^{2} \sin ^{2} \theta / 2 k$, Glen's condition never is valid $(\theta$ is the angle between the maximum slope of an obstacle and the average slope of the bed); but in the region where $\tau r^{2} \sin ^{2} \theta / 2 k<\rho g h<\tau r^{2} / k$ Glen's condition may or may not be valid. In this region the sliding velocity is double-valued. (It is interesting to note that 
Meier (private communication) has some field observations which indicate, through an indirect calculation, the occurrence of a double value in the sliding velocity of Nisqually Glacier.)

Figures 4 and 5 show regions of validity and non-validity of Glen's condition. In these figures glacier thickness $h$ is plotted versus shear stress for various values of the roughness factor $r$. The intermediate areas of these plots indicate the region within which $\beta_{\Lambda}$ can have either one of two values. Here the sliding velocity is double valued.

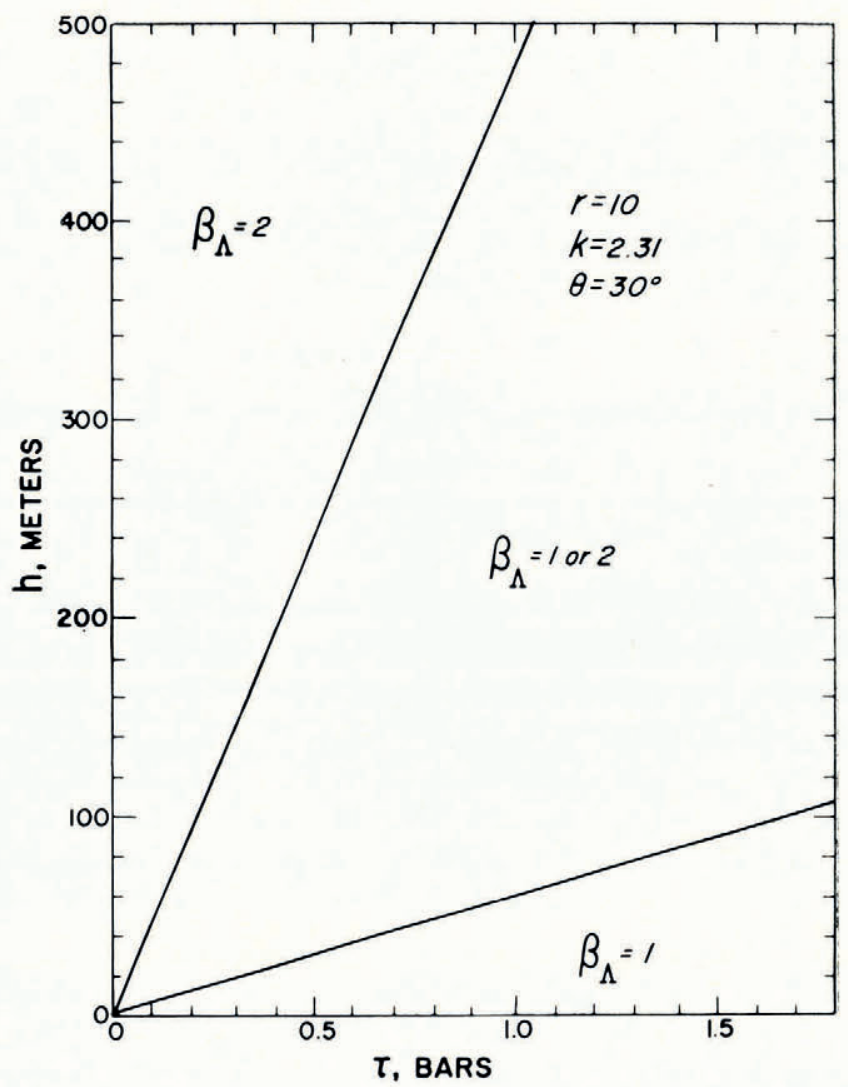

Fig. 4. Diagram of glacier thickness $h$ and shear stress $\tau$ showing the regions in which $\beta_{\Lambda}=I, \beta_{\Lambda}=2$ and $\beta_{\Lambda}=I$ or 2 . The roughness factor $r=10$ and $k=2 \cdot 3 I$. The ratio of maximum angle $\theta$ between slope of the surface of the obstacle and the average slope of the bed is assumed to be $30^{\circ}$

When Glen's condition does not hold, cavities form behind the controlling obstacles and also possibly behind obstacles larger than those of the controlling size. Lliboutry (1959) first predicted the existence of cavities at the bed of a glacier. His prediction was based on a model of a glacier bed, his washboard model, which is rather different than the one we have employed. Nevertheless the physical reason for the appearance of cavities in our model of a glacier bed is much the same as in his.

The length of the cavity which is formed behind an obstacle can be estimated as follows. The stress which causes sliding around an obstacle is $\tau r^{2} \mid k$, where $\beta=\mathrm{I}$. The sliding velocity is proportional to $\left(\tau r^{2} / k\right)^{n}$. Since the overburden pressure is $\rho g h$ the velocity with which the cavity is closed is proportional to $(\rho g h)^{n}$. Therefore the cavity behind an obstacle of size $\Lambda$ will be closed off at a distance from the obstacle which is of the order of 
$\Lambda\left(\tau r^{2} / k\right)^{n} /(\rho g h)^{n}$. The cross-sectional area of the cavity approaches zero at this distance. At the head of the cavity the cross-sectional area is that of the obstacle itself. The probability that another obstacle of size $\Lambda$ is directly down-stream from the obstacle increases the further down-stream one goes. A simple calculation shows that the probability is of the order of I at the distance $\Lambda r^{2}$. Therefore the length of the cavity cannot exceed $\Lambda r^{2}$.

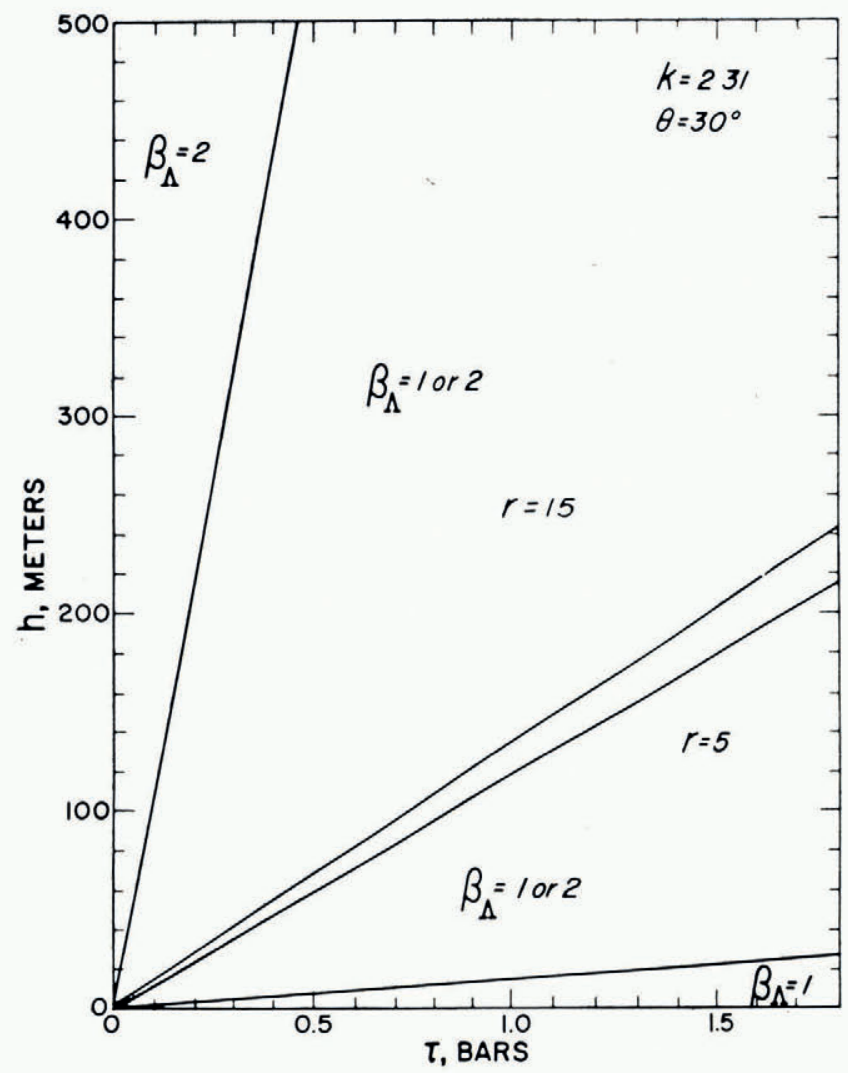

Fig. 5. Same diagram as Figure 4 except that $r=5$ and $r=I_{5}$

It is evident that when the length of the cavities becomes as long as $\Lambda r^{2}$ the bottom of the glacier touches the bed only at the tops of the obstacles. This is the condition fundamental to Lliboutry's theory of sliding (1959). I presented an argument (Weertman, r962) that this condition can occur only for extremely rapid sliding velocities such as would exist during the avalanching of thin ice slabs. The argument that we presented still is valid. If an appreciable fraction of a glacier loses contact with the bed through the formation of cavities the effective hydrostatic pressure at the bottom of the glacier is increased over the value $\rho g h$ by the factor $\mu$ (the area of the bed divided by the area of ice in contact with the bed). This increase in the hydrostatic pressure increases the rate of closure of a cavity. The length of a cavity now is of the order of $\Lambda\left(\tau r^{2} / k\right)^{n} /(\mu \rho g h)^{n}$.

The value of $\mu$ may be estimated easily. An area $(r \Lambda)^{2}$ of the bed contains one obstacle of size $\Lambda$. The area of the glacier bed underneath the cavity behind this obstacle is approximately $\Lambda^{2}\left(\tau r^{2} / k\right)^{n} /(\mu \rho g h)^{n}$. From these two areas the following equation is found for the ratio $\mu$ :

$$
\mu^{2}(\mu-\mathrm{I})=\left(\tau r^{2} / k\right)^{n} / r^{2}(\rho g h)^{n} .
$$


Figure 6 shows a plot of $\mu$ versus $h$ for various values of $r$. It is assumed that the shear stress $\tau=\mathrm{I}$ bar and $n=3$. (According to Figures 4 and 5 it is possible for $\beta_{\Lambda}$ to equal 2 and $\mu$ to equal $\mathrm{I}$ for any ice thickness to the right of the vertical hatches in Figure 6.) If the ice is riding on top of the obstacles, as it is pictured doing in Lliboutry's theory, $\mu$ is approximately equal to $r^{2}$. In order for $\mu$ to have this value under a stress of $\tau=\mathrm{I}$ bar and a roughness of $r=\mathrm{I} 5$, Io, or 5, the ice thickness must be less than $10 \mathrm{~m}$. This conclusion is in harmony with my previous discussion (Weertman, I 962) of Lliboutry's paper. It can be seen from Figure 6 that an appreciable separation of ice from rock can occur, although not to the extent envisaged by Lliboutry, for glacier thicknesses of the order of $100 \mathrm{~m}$.

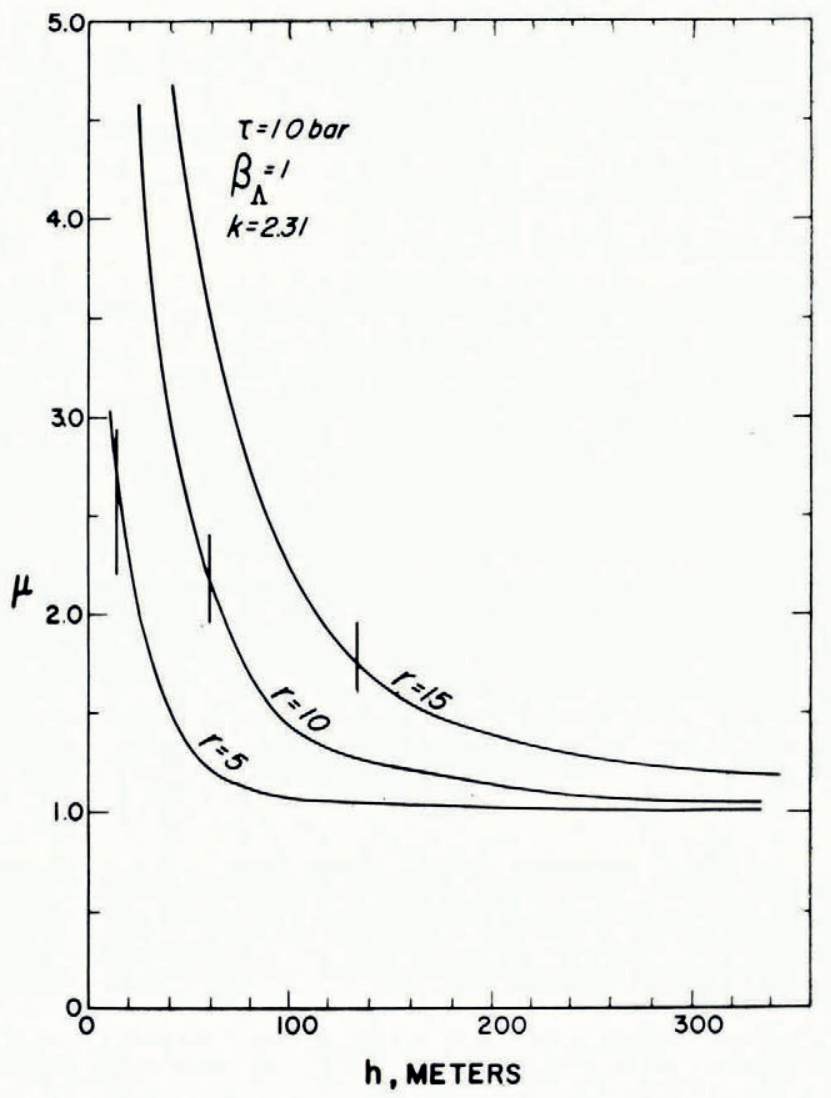

Fig. 6. Plot of the ratio $\mu$ (ratio of area of bed to area of ice in contact with bed) versus the thickness $h$ of a glacier when $\tau=\mathrm{I}$ bar, $k=2 \cdot 3 I$ and $\beta_{\Lambda}=I$

In Lliboutry's theory the ice separation at the bed profoundly influences the sliding velocity. It is to be emphasized strongly that the separations occuring in the present analysis do not have this strong influence on the velocity except when $\mu \approx r^{2}$. In fact so long as $\mu<r^{2}$ the sliding velocity is not influenced by separation.*

* This statement should be qualified to the extent that if $\mu$ is much larger than about 3 the effective resistance to sliding by obstacles smaller than $\Lambda$ is greatly reduced. The sliding rate thus will be raised by an amount equal to the increase in velocity which results from the presence of a water layer smaller in thickness than the controlling obstacle size. This velocity increase is discussed in the following section. It is much smaller than that found in Lliboutry's theory. 
Our analysis of cavities was based on the assumption that the cavities are free of water. Lliboutry also considered cavities filled with water. His treatment was criticized by the present author ([Union Géodésique et Géophysique Internationale], 1963, p. 67) as being incomplete. There is no way to estimate the magnitude of the water pressure in a cavity from his analysis, yet a knowledge of this pressure is important since the sliding velocity he derived depends sensitively upon it.

I should like now to give an argument in favor of the idea of Lliboutry that cavities formed by obstacles normally are filled with water. Consider the cavity whose cross-sectional and top views are shown in Figure 7 . If the cavity does not contain water the pressure $P^{*}$ of ice against rock at the periphery of the cavity will be smaller than the pressure $P$ at the ice-rock interface a distance away from the cavity. This conclusion can be demonstrated quantitatively from Nye's theory (1953) of the closing of tunnels for the case when $n$ of Glen's creep equation is equal to 3 . (If $n$ were smaller than about $2, P^{*}$ would be larger than $P$ according to Nye's theory.) The water at the bottom of a glacier which exists in the ice-rock interface will always flow down a pressure gradient. Since the pressure gradient is towards the cavity a water-free cavity will become filled with water.

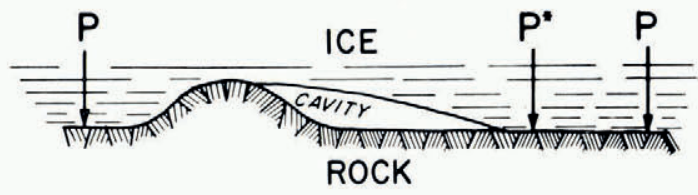

(a)

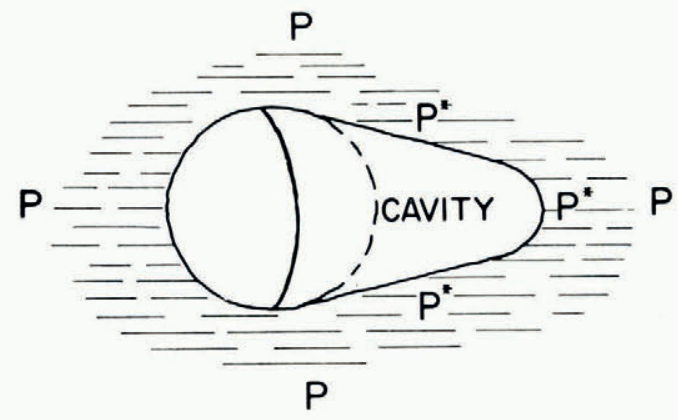

(b)

Fig. 7. Water-free cavity behind an obstacle $(a)$ cross-sectional view, $(b)$ looking down from a point directly above the cavity. The pressure $P$ is the average hydrostatic pressure at the bed and the pressure $P^{*}$ is that exerted near the cavity $\left(P^{*}<P\right)$

Suppose that an isolated cavity is filled with water. Assume that for a constant sliding velocity the cavity is in a steady-state condition. It is growing neither smaller nor larger. The water pressure at the bottom of the cavity must be identical with that under the ice. Otherwise water would flow into or out of the cavity. At the top of the cavity the water pressure could differ from the pressure in the ice by an amount which at most is of the order of $\left(\rho_{w}-\rho\right) g \Lambda$, where $\rho_{w}$ and $\rho$ are the densities of water and ice respectively. For an obstacle $\mathrm{I} \mathrm{cm}$. in size this pressure difference is of the order of $\mathrm{IO}^{-4}$ bar. Therefore only a negligibly small pressure difference is available for causing the closure of the cavity. (In a steady-state condition the closure is exactly balanced by the sliding process which opens up the cavity.) Contrary to our assumption the isolated cavity cannot be in a steady-state condition. If the cavity remains 
completely filled with water it must become longer and longer since there is insufficient pressure available to close it off. Eventually it will connect with other cavities. When enough cavities interconnect the water within them can drain off. Once this happens the average diameter of a cavity will decrease through the creep flow of ice until the flow of water is so restricted that the cavity again can be completely filled with water. The cavity would have a tapered profile in the direction of ice flow similar to Figure 7 except that it would not be completely closed off at its down-stream end. The length of the tapered cavity would depend not only on the size of the obstacle, the roughness, and the shear stress acting across the bed, but also on the amount of water flowing at the bottom of a glacier. If the amount of water flow is large the average diameter of interconnecting cavities must be large in order to accommodate it. If it is small the average diameter will be small. In the latter situation the total area of the water-filled cavities at the glacier bed would be about the same as for the case in which the cavities were assumed to be water free. The velocity of sliding in this situation would be the same regardless of whether the cavities were water-free or water-filled.

If the average diameter of a cavity remains large because of an abundance of melt-water supply the interconnecting water-filled cavities can be approximated in a limiting case by a sheet of water of uniform thickness at the bed of a glacier. The thickness of such a sheet of water was shown (Weertman, 1962) to be determined by the amount of water flowing through any section of the bed. We consider the effect of a water layer on the sliding velocity in the following section.

\section{Effect of the water layer at the bed of a glacier}

The field observations of Elliston ([Union Géodésique et Géophysique Internationale], I 963 , p. 65-66) on the Gornergletscher show convincingly that water at the bottom of a glacier can change markedly the velocity of glacier movement. He finds that in the winter the glacier velocity is $20-50$ per cent slower than the annual mean velocity, and the summer velocity exceeds the average by $20-80$ per cent. These changes can be understood if melt water acts as a lubricant at the bottom of a glacier. I have shown (Weertman, ig62) that if the water layer at the bottom of a glacier is thicker than the height of the controlling obstacles an increase in the sliding velocity will occur.

In our previous treatment it was found that the water layer has no effect on the sliding rate until the thickness of the water layer is as great as the height of the controlling obstacles. We should like to point out now that a water layer with a thickness an order of magnitude smaller than the controlling obstacle size can cause an appreciable increase in the sliding velocity. The reason that in the present theory a water layer of such small thickness can affect the sliding rate may be seen from equations (5) and (6). No obstacles smaller than the thickness of the water layer can cause a hindrance to the sliding motion. Thus the effective shear stress $\tau_{i}$ in equation (5) acting on these obstacles is zero. As a result the effective stress on the larger obstacles is raised and the sliding velocity is increased.

When the thickness $d$ of the water layer is smaller than $\Lambda$, equation (7a) for $\tau_{\Lambda}$ becomes

$$
\tau=\tau_{\Lambda}\left[\mathrm{I}+2^{\mathrm{I} / n}\left\{(\mathrm{IO})^{\mathrm{I} / n}-\mathrm{I}\right\}+\frac{1}{5}\left\{\mathrm{I}+\frac{1}{10}+\left(\frac{1}{10}\right)^{2}+\ldots\left(\frac{1}{10}\right)^{m}\right\}\right] .
$$

The number of terms in the series $\mathrm{I}+\frac{1}{10}+\ldots$ depends on the thickness of the water layer. If the water layer is equal to or larger than $\Lambda /$ io no term is retained in the series. If the water layer is equal to or larger than $\Lambda / \mathrm{I}$ oo but smaller than $\Lambda / \mathrm{I}$ o the first term only is retained; if the layer is larger than or equal to $\Lambda /$ Iooo but smaller than $\Lambda / 100$ the first two terms are retained; and so on. If the water layer is somewhat thicker than $\Lambda /$ io but not so thick as $\Lambda$, equation (II) reduces to

$$
\tau=(2 \cdot 092) \tau_{\Lambda}
$$

or $k=2 \cdot 092$. This value of $k$ is almost io per cent smaller than the previous value of $2 \cdot 3 \mathrm{I} 4$. Thus the sliding velocity, which is inversely proportional to the square of $k$, is approximately 
20 per cent larger than it would be if the water layer thickness were very much smaller. This is an appreciable increase in the sliding velocity. If the water layer thickness were of the order of $\Lambda / \mathrm{I}$ oo, $k$ would be $\mathrm{I}$ per cent smaller and the sliding rate 2 per cent faster, and so on for still smaller thicknesses of the water layer.

If the water layer is thicker than the height of the controlling obstacles, equations (5) and (6) predict that the sliding velocity $S^{*}$ will be

$$
S^{*}=b B \gamma \Lambda^{\prime}\left(\tau \gamma / \beta^{\prime} k\right)^{n_{\gamma^{2} n}}
$$

where $\beta^{\prime}$ is the value of $\beta$ for the obstacles which are just bigger than the thickness of the water layer and $\Lambda^{\prime}$ is the size of these obstacles. The term $k$ is equal to $\mathrm{I} \cdot 82$ if the value of $\beta$ is the same for all obstacles larger than the thickness of the water layer, and $k=2 \cdot 04$ if $\beta^{\prime}=\mathrm{I}$ for obstacles of size $\Lambda^{\prime}$ and $\beta=2$ for all larger obstacles.

Figure 8 shows a plot of the ratio of the sliding velocity $S^{*}$ when an appreciable water layer is present to the ordinary sliding velocity $S$ versus the thickness of the water layer. (It is assumed that $\beta=2$ for all obstacles.) The plot is a step function because we have employed a discrete rather than continuous distribution function for obstacle sizes. It is expected that the curve of $S * / S$ versus water layer thickness for a continuous distribution function approximates the dashed curve drawn in this figure.

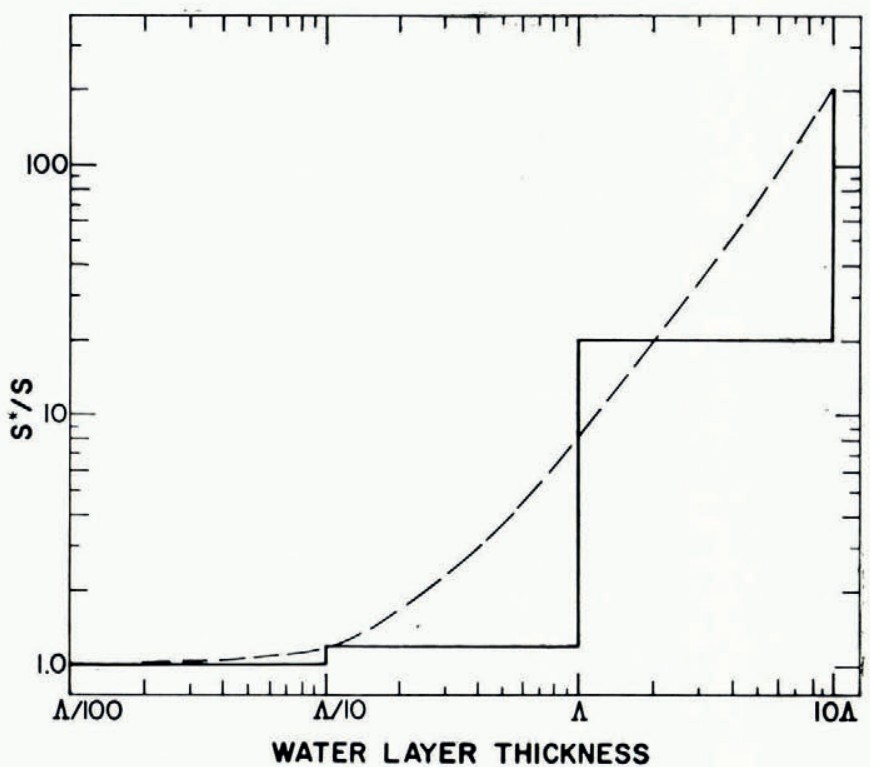

Fig. 8. Plot of the ratio $S^{*} / S$ versus thickness of the water layer at the bed. ( $S^{*}$ is the sliding velocity when an appreciable water layer is present and $S$ the sliding velocity when the water layer thickness is extremely small.) The solid curve gives values of $S^{*} / S$ for the bed with the discrete spectrum of obstacle sizes considered in the text. The dashed curve shows a possible variation of $S^{*} / S$ with the thickness of the water layer for a bed with a continuous spectrum of obstacle sizes

Table I. Controlling Obstacle Size and Roughness Factor for a Sliding Velocity of 80 m./Yr. under a i bar Shear Stress

Controlling size $\Lambda \mathrm{mm}$. Roughness factor $r$
Older Theory $\quad \beta=\mathrm{I}$

(Weertman, 1962) $k=2 \cdot 3$

$\mathrm{I} \cdot 8$

I $6 \cdot 6$

$3 \cdot 5$
$14 \cdot 2$

$\begin{array}{cc}\beta=2 & \beta_{\Lambda}=\mathrm{I} \\ k=2 \cdot 3 & k=3 \cdot 4 \\ 6 \cdot 0 & 3 \cdot 55 \\ \mathrm{I} 8 \cdot 4 & \mathrm{I} 7 \cdot 2\end{array}$ 


\section{Discussion And Summary}

In its essential features the sliding theory just presented is the same as the simpler theory developed in earlier papers (Weertman, I957, 1958, 1962). The new values for the sliding velocity and the controlling obstacle size are approximately the same as those found previously. Table I shows that controlling obstacle sizes and roughness factors required for a sliding velocity of $80 \mathrm{~m}$. a year under a shear stress $\tau$ of I bar. The new roughness factors are about the same as the old. The controlling obstacle size is a factor of 2 to 3 larger than that previously calculated. It can be seen that the more refined calculation does not lead to any significant difference in the sliding velocity or the obstacle size. It is assumed in the new calculated values that the constant factors $a$ and $b$ appearing in the sliding equations for $S_{1}$ and $S_{2}$ (equations ( $\mathrm{rb}$ ) and (3b)) are unity. These constant factors can be determined only by experimental tests. It seems unlikely that laboratory tests will give values for these terms which differ much from one.

Although the actual values for the sliding velocity and the controlling obstacle size have not been changed much by the new calculations several interesting results not contained in the older theory have come to light. The most interesting of these (see dashed curve of Figure 8) is the fact that a water layer smaller in thickness than the height of the controlling obstacles can change the sliding velocity by an amount of the order of 40 per cent to Ioo per cent. Thus if the obstacle sizes listed in Table I are representative the changes in the flow rate observed by Elliston on the Gornergletscher could have been produced by a water layer of only $0.35 \mathrm{~mm}$. to $0.60 \mathrm{~mm}$. in thickness. This new result means that melt water may influence the flow rate of glaciers much more than had been suspected previously.

The relaxation of the implicit assumption in the earlier version of the theory that Glen's condition always holds leads to the existence of a double-valued sliding velocity in a certain range of values of the thickness of a glacier. The two velocities in this double-valued range differ by a factor which is approximately equal to 2 or 3 .

When Glen's condition does not hold cavity formation occurs behind obstacles at the bed. Such cavities were predicted previously by Lliboutry. In Lliboutry's theory the cavity formation is so extensive that the glacier only sits on the tops of obstacles. I had previously shown (Weertman, I 962) that for a glacier of a typical thickness this condition can occur only if the glacier is sliding at velocities which are $\mathrm{IO}^{7}$ to ${ }_{10} 0^{8}$ larger than those actually observed. (Lliboutry also considered the situation in which the glacier rested on top of obstacles as well as on top of the water trapped in the hollows of his washboard model of a glacier bed. This situation of his would correspond to the case considered in this paper in which the water layer at the bed of a glacier is sufficiently thick to have an influence on the rate of sliding. Contrary to what Lliboutry concluded we do not find that the pressure of water in the water layer has any influence on the sliding velocity.)

Lliboutry's theory actually represents an extreme limiting case of the analysis of cavity formation developed in this paper. This extreme case is not likely to occur in nature unless the ice thickness is small (less than Io m.), or the ice velocity is extremely large, as would occur in avalanching ice slabs, or the shear stress at the bottom of an ice mass is considerably larger than I bar. (Lliboutry's theory probably is valid at the snout of a glacier where the ice thickness becomes less than ro $\mathrm{m}$.) Under the thinner parts of a glacier (less than $100 \mathrm{~m}$. in thickness) cavities should form and of course have been observed to exist.

The theory of the sliding of glaciers that has been developed in this paper is more general than that which I presented in the past. That earlier theory as well as Lliboutry's theory are contained as special cases in this more general theory.

\section{Acknowledgements}

I wish to thank Professors Barclay Kamb and Edward LaChapelle for the opportunity of seeing the preliminary draft of their paper. I also wish to thank Dr. Mark Meier for a dis- 
cussion on his observations on Nisqually Glacier which indicated a possible double-valued sliding velocity. Meier's observations were a strong motivation for developing the analysis of certain sections in this paper. I am indebted to Dr. John Glen for his comments on a preliminary version of this paper.

\section{MS. received 14 February 1964}

\section{REFERENCES}

Briggs, L. J. 1950. Limiting negative pressure of water. Fournal of Applied Physics, Vol. 21, No. 7, p. 721-22.

Fisher, J. C. 1950. The limiting hydrostatic tension of water near o C. Fournal of Applied Physics, Vol. 21, No. I0, p. 1068.

Goldthwait, R. P. 1960. Study of ice cliff in Nunatarssuaq, Greenland. U.S. Snow, Ice and Permafrost Research Establishment. Technical Report 39.

Kamb, W. B., and LaChapelle, E. R. 1963. Direct observation of the mechanism of basal slip in a temperate glacier. Union Géodésique et Géophysique Internationale. Association Internationale d'Hydrologie Scientifique. Assemblée générale de Berkeley, 19-8-31-8 1963. Commission des Neiges et des Glaces, p. 224. [Abstract.]

$\mathrm{Kamb}, \mathrm{W}$. B., and LaChapelle, E. R. I964. Direct observation of the mechanism of glacier sliding over bedrock. fournal of Glaciology, Vol. 5, No. 38, p. $159-72$.

Lliboutry, L. 1959. Une théorie du frottement du glacier sur son lit. Annales de Géophysique, Tom. 15, No. 2, p. $250-65$.

Lliboutry, L., and Brepson, R. 1963. Le viscosimètre à glace de Grenoble. Union Géodésique et Géophysique Internationale: Association Internationale d'Hydrologie Scientifique. Assemblée générale de Berkeley, 19-8-31-8 1963. Commission des Neiges et des Glaces, p. $13^{8-43}$.

Nye, J. F. 1953. The flow law of ice from measurements in glacier tunnels, laboratory experiments and the Jungfraufirn borehole experiment. Proceedings of the Royal Society, Ser. A, Vol. 219, No. 1 139, p. 477-89.

[Union Géodésique et Géophysique Internationale.] i 963 . Colloque d'Obergurgl (suite). Bulletin de l'Association Internationale d'Hydrologie Scientifique, 8e An., No. 2, p. 50-142.

[Union Géodésique et Géophysique Internationale.] In press. [Discussion at Berkeley meeting of Commission of Snow and Ice, 1963 , to be published in Bulletin de l'Association Internationale d'Hydrologie Scientifique.]

Weertman, J. 1957. On the sliding of glaciers. Fournal of Glaciology, Vol. 3, No. 21, p. 33-38.

Weertman, J. I 958 . Transport of boulders by glaciers and ice sheets. Bulletin de l'Association Internationale d'Hydrologie Scientifique, No. 10, p. 44.

Weertman, J. 1952. Catastrophic glacier advances. Union Géodésique et Géophysique Internationale. Association Internationale d'Hydrologie Scientifique. Commission des Neiges et Glaces. Colloque d'Obergurgl, 10-9-18-9 1962, p. 31-39. 